\title{
Pediatric Warthin Tumor of Parotid Gland
}

\author{
Mitsuhiro Aoki ${ }^{\mathrm{a}, \mathrm{c}}$, Takesumi Nishihori ${ }^{\mathrm{b}}$, Natsuko Obara ${ }^{\mathrm{b}}$, \\ Hisakazu Kato $^{\text {, }}$ Keisuke Mizuta ${ }^{\text {b }}$
}

\begin{abstract}
The benign neoplasms of parotid glands in children are mostly pleomorphic adenoma and Warthin tumor is extremely rare. The differential diagnosis of Warthin tumor from mucoepidermoid carcinoma in pediatric cases before the surgery is often difficult and it is not easy to determine the surgical design. We reported an 8-yearold girl with Warthin tumor in left parotid gland. The magnetic resonance imaging (MRI) of the mass revealed comparatively lower value of the apparent diffusion coefficient value, which suspected the Warthin tumor. She therefore underwent superficial parotidectomy via modified facelift incision. She has never suffered from facial palsy and Frey syndrome for 2 years after the surgery and the cosmetic result was satisfactory. It suggests that precise preoperative diagnosis is important because the surgery for pediatric cases with parotid gland neoplasm should be designed to remove the tumor completely with an adequate margin.
\end{abstract}

Keywords: Warthin tumor; Parotid gland; Diagnosis

\section{Introduction}

Neoplasms of the salivary glands in children are rare, less than $5 \%$ of all salivary gland tumors. In addition, salivary neoplasms account for less than $10 \%$ of all pediatric head and neck tumors [1]. A large collective study including 472 pediatric cases of salivary gland neoplasms has demonstrated that the ratio of malignancy in salivary gland tumors in children was higher (49\%), which was much higher than

Manuscript accepted for publication May 8, 2014

${ }^{a}$ Medical Information Division, Gifu University Hospital, Gifu, Japan ${ }^{b}$ Department of Otolaryngology, Gifu University Graduate School of Medicine, Gifu, Japan

${ }^{c}$ Corresponding Author: Mitsuhiro Aoki, Medical Information Division, Gifu University Hospital, 1-1 Yanagido, Gifu city, 501-1194 Gifu, Japan.

Email: aoki@gifu-u.ac.jp

doi: http://dx.doi.org/10.14740/ijcp149w that in adults (15-25\%) [2]. The benign neoplasms of parotid glands in children are mostly pleomorphic adenoma [3, 4]; however, few pediatric case with Warthin tumor has been reported in English literature [5]. We report here an 8-year-old girl with Warthin tumor of the parotid gland.

\section{Case Report}

An 8-year-old girl was referred to our department because of a painless swelling in the inferior part of the left earlobe, which had been enlarging twice in the size over the course of 2 years. She never showed other symptoms except for the parotid swelling, which involved a relatively soft, nonmobile, smooth induration $30 \mathrm{~mm}$ in diameter covered by normal skin.

A fine-needle aspiration biopsy specimen from the lesion showed some lymphocytes and macrophages, but no atypical cells. Magnetic resonance imaging (MRI) examination revealed a round mass presenting both cystic and solid lesions within the superficial lobe of the left parotid gland. The solid lesion showed a relative low signal round mass on T2 MRI. The mass with clear margins was slightly enhanced by gadolinium (Fig. 1). The apparent diffusion coefficient (ADC) value of the mass was comparatively low $(1.022 \times$ $10^{-3} \mathrm{~mm}^{2} / \mathrm{s}$ ), which was not as low as the malignant lymphoma and was not as high as pleomorphic adenoma $[6,7]$.

She underwent superficial parotidectomy via a modified facelift incision. The posterior branch of the great auricular nerve, the marginal branch and cervical branch of the facial nerve were preserved (Fig. 2A). Finally the tumor encapsulated by fibrous tissue was completely resected with a part of normal tissues. She has never suffered from facial palsy and Frey syndrome for 2 years after the surgery and the cosmetic result was satisfactory (Fig. 2B).

The resected tumor was pathologically well encapsulated lesions with cystic and solid areas, which consisted of an eosiophilic oncocytic epithelial cell component arranged in double layers. A variable amount of lymphoid tissue represented with germinal centers (Fig. 3). It was therefore diagnosed as Warthin tumor. The resected margin was pathologically negative. 


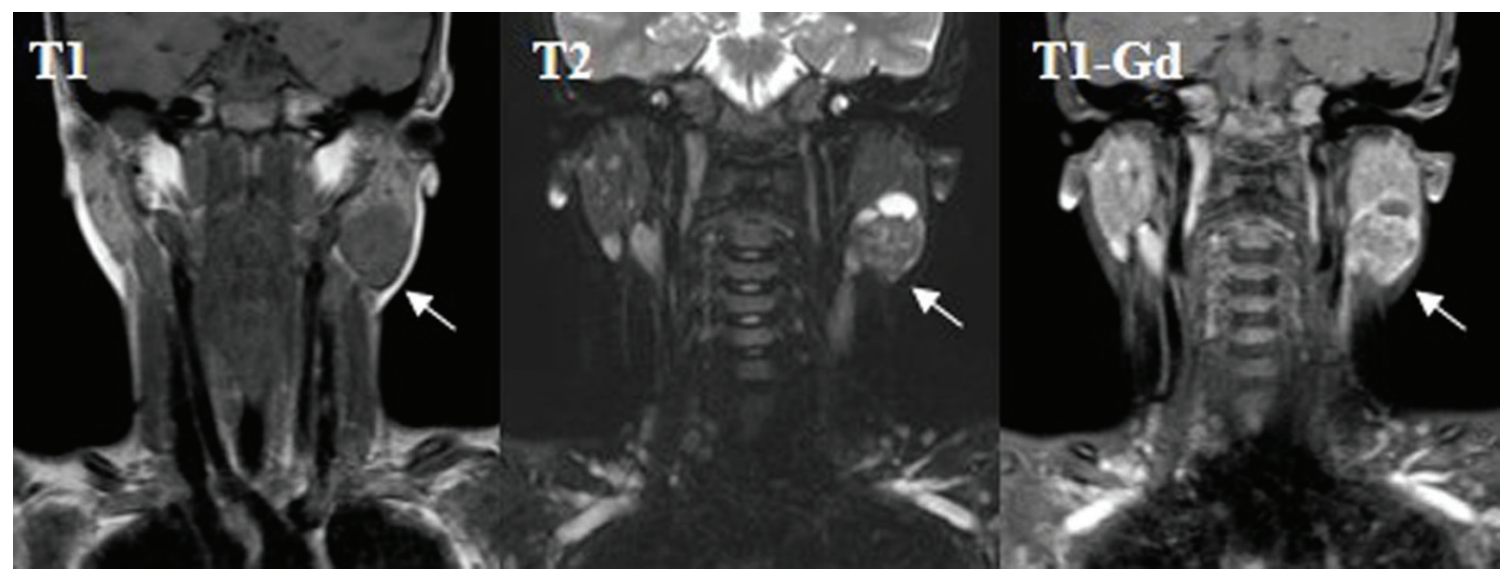

Figure 1. Magnetic resonance imaging (MRI) examination revealed a round mass presenting both cystic and solid lesions within the superficial lobe of the left parotid gland. T1 MRI showed a low signal mass (T1) and T2 MRI showed a relative low signal round mass (T2). The mass with clear margins was slightly enhanced by gadolinium (T1-Gd). The arrows show the tumor mass.

\section{Discussion}

The neoplasms of salivary gland are rare in children; however, the frequency of malignancy is higher in children compared to adults. The most common malignant neoplasms are mucoepidermoid carcinomas [8]. A limited clinical symptom such as facial nerve palsy in patients with parotid gland masses may allow the diagnosis of malignancy. However, the differentiation between benign and malignant is not possible by clinical examination only in most of patients with salivary gland tumors. Fine-needle aspiration cytology (FNAC) may provide helpful information to differentiate benign from malignant salivary gland tumor. However, FNAC may be difficult to be performed for young children. Additionally, the differentiation of a few benign and malignant lesions might be impossible $[9,10]$. A risk of FNAC might be a possible spread of tumor cells, which can lead to a higher likelihood of local recurrence, especially in pleomorphic adenomas and malignant lesions [11].

Recent pre-operative imaging has a major role in surgical planning and the ADC value of carcinomas as the quantitative parameter of diffusion-weighted MRI has been shown to be significantly smaller than that of benign solid tumors. Average ADC value of Warthin tumors $\left(0.96 \times 10^{-3} \mathrm{~mm}^{2} / \mathrm{s}\right)$ has been reported to be significantly lower than that in most of malignant lesions $\left(1.19 \times 10^{-3} \mathrm{~mm}^{2} / \mathrm{s}\right)[6,7,12]$. This finding might be attributed to the intense lymphoid accumulation in the stroma and proliferation of the epithelial component leading to a decrease in the extracellular extravascular space and therefore a decrease in the ADC value [13]. However, other study reported that mucoepidermoid carcinomas, acinic cell carcinomas and basal cell adenocarcinomas were not differentiable from Warthin tumors on the basis of ADC values solely [7]. Our case also showed the relative lower value

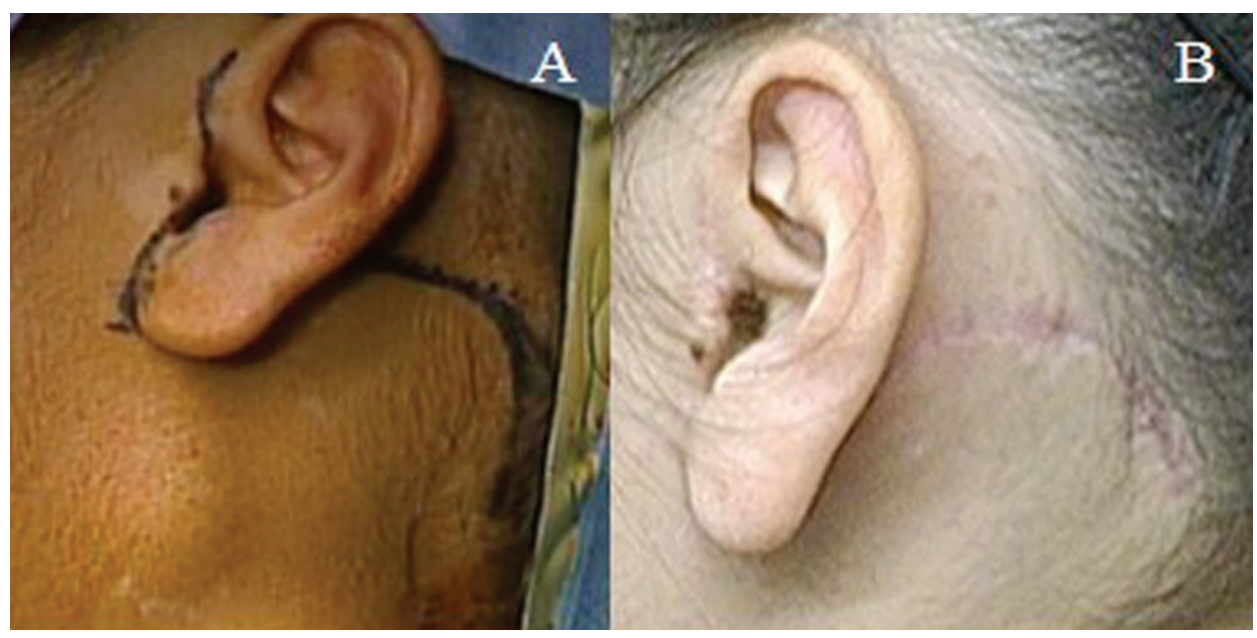

Figure 2. A design of facelift incision for the parotidectomy (A) and the postoperative wounds 3 months after the surgery (B). 


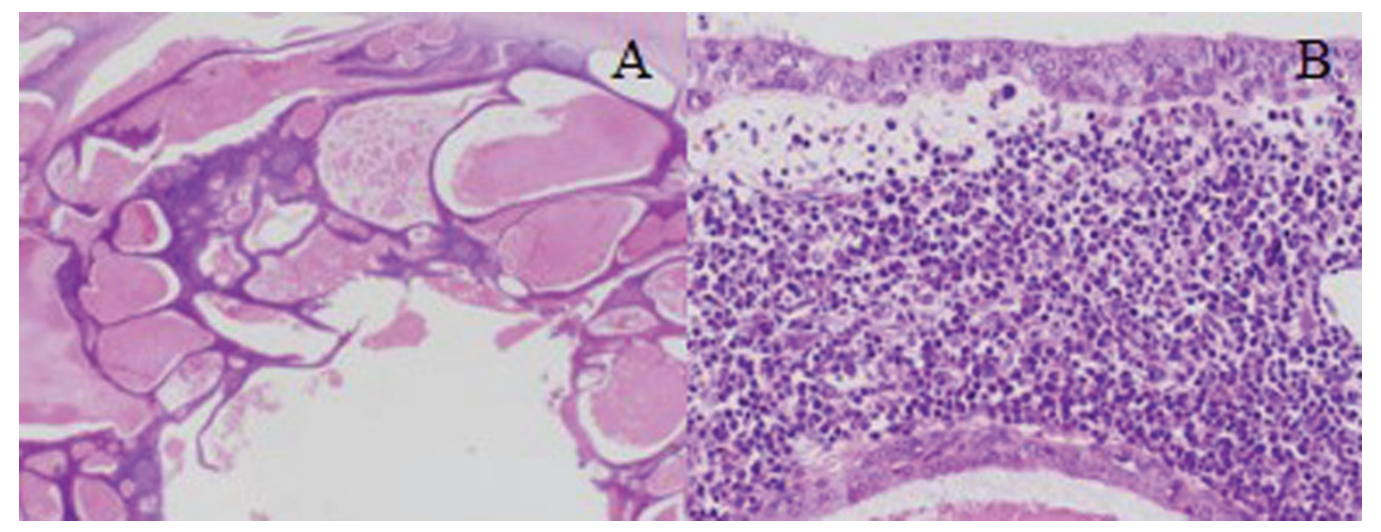

Figure 3. The histopathological findings revealed well encapsulated lesions with cystic and solid areas consisting of an eosiophilic oncocytic epithelial cell component arranged in double layers (A: examination on low power). A variable amount of lymphoid tissue represented with germinal centers (B: examination on high power).

of ADC, which suspected the Warthin tumor; however, only ADC value could not exclude mucoepidermoid carcinoma.

The surgical treatment is the first choice for parotid gland tumors. The enucleation or local excision for parotid gland tumor had been previously performed in children; however, the recurrent rates were very high [2]. Recently the superficial parotidectomy or the total parotidectomy has been a standard operation for parotid gland tumors, resulting in that the recurrence significantly decreased. The slight S-curve incision from preauricular region halfway down the neck has been generally adopted for the parotidectomy. This approach provides excellent surgical exposure of the entire parotid gland; however, it inevitably leaves a visible scar. Therefore, a facelift incision for parotidectomy has been frequently performed for female and pediatric patients especially. The cosmetic results are significantly superior to those of the traditional S-curve incision although the facelift incision approach may not be for known malignant tumors invading to parapharyngeal space and recurrent tumors [14].

An assessment of risk and duration of postparotidectomy facial nerve dysfunction is an important component of preoperative counseling. The facial nerve lies in a more superficial location in infants than in adults because of an underdeveloped mastoid process. The mastoid process progressively develops since the birth and the facial nerve assumes a more medial position. It should be noted that a more superficial location places the nerve at an increased risk for injury [15].

The enucleation for Warthin tumor has been described to be enough for the surgical treatment [16]; however, it is difficult to acquire the correct pathological diagnosis before the operation in most of pediatric cases with salivary gland tumors. The inoperative frozen section provides efficient information for the treatment; however, it is not appropriate for diagnosis of salivary gland neoplasms and it increases risks of the facial nerve damage and the tumor spillage [1]. It indicates that the surgery for pediatric cases with parotid gland neoplasm should be designed to remove the tumor completely with an adequate margin. The superficial parotidectomy was designed for our case because the differential diagnosis from mucoepidermoid carcinoma was difficult before the surgery, and the Warthin tumor could be completely resected without any complications.

\section{Conflict of Interest}

The authors declare that they have no conflict of interest.

\section{References}

1. Callender DL, Frankenthaler RA, Luna MA, Lee SS, Goepfert H. Salivary gland neoplasms in children. Arch Otolaryngol Head Neck Surg. 1992;118(5):472-476.

2. Shikhani AH, Johns ME. Tumors of the major salivary glands in children. Head Neck Surg. 1988;10(4):257263.

3. Orvidas LJ, Kasperbauer JL, Lewis JE, Olsen KD, Lesnick TG. Pediatric parotid masses. Arch Otolaryngol Head Neck Surg. 2000;126(2):177-184.

4. Kessler A, Handler SD. Salivary gland neoplasms in children: a 10-year survey at the Children's Hospital of Philadelphia. Int $\mathrm{J}$ Pediatr Otorhinolaryngol. 1994;29(3):195-202.

5. Schuller DE, McCabe BF. Salivary gland neoplasms in children. Otolaryngol Clin North Am. 1977;10(2):399412.

6. Habermann CR, Arndt C, Graessner J, Diestel L, Petersen KU, Reitmeier F, Ussmueller JO, et al. Diffusion-weighted echo-planar MR imaging of primary parotid gland tumors: is a prediction of different histologic subtypes possible? AJNR Am J Neuroradiol. 2009;30(3):591-596. 
7. Ikeda M, Motoori K, Hanazawa T, Nagai Y, Yamamoto $\mathrm{S}$, Ueda T, Funatsu H, et al. Warthin tumor of the parotid gland: diagnostic value of MR imaging with histopathologic correlation. AJNR Am J Neuroradiol. 2004;25(7):1256-1262.

8. Patients'powerandPACE.Lancet.2011;377(9780):1808.

9. Brennan PA, Davies B, Poller D, Mead Z, Bayne D, Puxeddu R, Oeppen RS. Fine needle aspiration cytology (FNAC) of salivary gland tumours: repeat aspiration provides further information in cases with an unclear initial cytological diagnosis. Br J Oral Maxillofac Surg. 2010;48(1):26-29.

10. Ashraf A, Shaikh AS, Kamal F, Sarfraz R, Bukhari MH. Diagnostic reliability of FNAC for salivary gland swellings: a comparative study. Diagn Cytopathol. 2010;38(7):499-504.

11. Supriya M, Denholm S, Palmer T. Seeding of tumor cells after fine needle aspiration cytology in benign parotid tumor: a case report and literature review. Laryngoscope. 2008;118(2):263-265.
12. Yabuuchi H, Matsuo Y, Kamitani T, Setoguchi T, Okafuji T, Soeda H, Sakai S, et al. Parotid gland tumors: can addition of diffusion-weighted MR imaging to dynamic contrast-enhanced MR imaging improve diagnostic accuracy in characterization? Radiology. 2008;249(3):909916.

13. Wang J, Takashima S, Takayama F, Kawakami S, Saito A, Matsushita T, Momose M, et al. Head and neck lesions: characterization with diffusion-weighted echoplanar MR imaging. Radiology. 2001;220(3):621-630.

14. Terris DJ, Tuffo KM, Fee WE, Jr. Modified facelift incision for parotidectomy. J Laryngol Otol. 1994;108(7):574-578.

15. Farrior JB, Santini H. Facial nerve identification in children. Otolaryngol Head Neck Surg. 1985;93(2):173176.

16. Batori M, Mariotta G, Giovannone G, Casella G, Casella MC. Warthin's tumor of parotid gland: treatment of a retroneural lesion by enucleation. Eur Rev Med Pharmacol Sci. 2002;6(5):105-111. 